\title{
Geomagnetic activity forcing of the Northern Annular Mode via the stratosphere
}

\author{
D. R. Palamara and E. A. Bryant \\ University of Wollongong, School of Geosciences, NSW 2522, Australia \\ Received: 1 May 2003 - Revised: 8 October 2003 - Accepted: 12 November 2003 - Published: 19 March 2004
}

\begin{abstract}
We consider various aspects of the link between solar-modulated geomagnetic activity and the Northern Annular Mode (NAM). Our results indicate that the geomagnetic forcing of atmospheric circulation in the Northern Hemisphere is temporally and seasonally restricted, modulated by the Quasi-Biennial Oscillation (QBO), and reliant on stratosphere-troposphere coupling. When the data are restricted to January values after 1965 , for years in which the January QBO is eastwards, the correlation coefficient between the geomagnetic AA index and the NAM is 0.85 . These results can account for many of the enigmatic features of Northern Hemisphere circulation.
\end{abstract}

Key words. Meterology and atmospheric dynamics (general circulation, climatology)

\section{Introduction}

Changes in atmospheric circulation, as represented by the Northern Annular Mode (NAM), impact upon global climate. Despite the important role that the NAM and the closely associated North Atlantic Oscillation (NAO) index play in recent climate change (Hurrell, 1996; Thompson et al., 2000) their forcing mechanisms and behaviour are not well understood (Perry, 2000). For example, it is not clear to what extent changes in the NAO are an accumulation of stochastic weather events (Stephenson et al., 2000), the product of ocean-atmosphere coupling (Marshall et al., 2001), or the result of internal atmospheric dynamics, possibly originating in the stratosphere (Perlwitz and Graf, 1995). There are also a number of specific uncertainties about these atmospheric modes. Researchers note a period of uncharacteristically low values in the NAO and NAM indices between the 1950s and 1970s (Greatbatch, 2000), followed by a strong positive trend extending to the present day (Stephenson et al., 2000). Although Wunsch (1999) has described similar nonstationary

Correspondence to: D. R. Palamara

(daniel.palamara@telstra.com) periods in a synthetic NAO index, one cannot exclude the possibility that the recent changes in these indices of atmospheric circulation are deterministic. The literature also expresses uncertainty about the origin of decadal variations evident since the 1960s (Hurrell, 1995), the year-to-year winter persistence of anomalies (Stephenson et al., 2000), and the nature of interannual variations of the NAO (Feldstein, 2000).

There are a number of reasons to suspect that the aforementioned uncertainties can be explained in part by solar activity, as represented by geomagnetic activity. For example, geomagnetic activity also exhibits an uncharacteristic period of low values centred in the 1960s, and its power spectrum is dominated by decadal variations. The most compelling evidence that the recent changes in these atmospheric indices are related to solar-modulated geomagnetic activity is found in Bucha and Bucha (1998), who presented correlations linking the NAO to geomagnetic activity, and more recently, in Thejll et al. (2003), who also correlated geomagnetic activity to the North Atlantic Oscillation. However, many aspects of this relationship remain unexplored. These aspects relate to the nature of this relationship at different time scales, especially the interannual level, as well as its temporal and seasonal characteristics, and its possible dependence on the phase of the Quasi-Biennial Oscillation (QBO). Correlations presented in other solar-climate studies are often strongly dependant on the phase of the QBO; Labitzke and van Loon (2000), for instance, noted that correlations between stratospheric geopotential heights in the Arctic and the 11-year solar cycle are positive during the QBO west phase, negative during the QBO east phase, and nonexistent when the data are not separated according to the QBO phase. In this paper, we test the hypothesis that geomagnetic activity is a significant forcing mechanism behind recent changes in Northern Hemisphere atmospheric circulation changes and examine the aforementioned aspects of the relationship. 


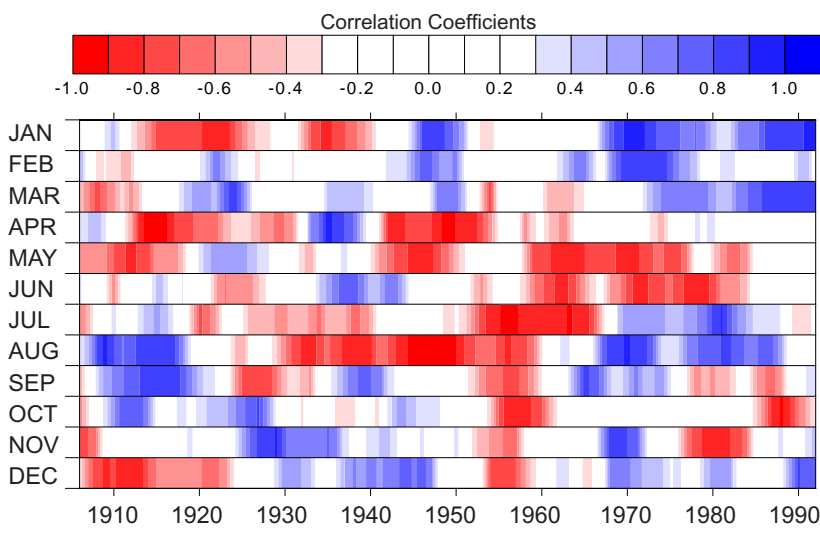

Fig. 1. Sliding correlations between the decadal variations of the geomagnetic AA and NAM indices. The decadal variations were extracted by applying an unweighted five-point moving average to the original data. The sliding correlation window width is 11 years, with a one-year increment. Correlation coefficients below 0.30 are unshaded. Note the period of consistently high, positive correlations for the January data, from approximately 1967 onwards. This indicates that the geomagnetic forcing of the Northern Hemisphere circulation is temporally and seasonally restricted.

\section{Data and methods}

Monthly values of the (NAM) are provided online by David Thompson at the Annular Modes website (http://www.atmos. colostate.edu/ao/Data/ao_index.html). The monthly NAM indices used in our study span 1899 to 2000 , and are the same as those used by Thompson and Wallace (2000) and Thompson et al. (2000). The NAM indices were derived, by their providers, from the regression of monthly anomaly fields on the leading principal component of sea level pressure data in the Northern Hemisphere. The geomagnetic AA index was obtained from the NOAA NGDC Solar Terrestrial Physics Division website (ftp://ftp/ngdc.gov/STP/SOLAR \ _DATA/RELATED_INDICES), and is available from 1868 to 1999 . The AA index, which is measured in nanoTesla (nT), was devised by Mayaud (1972) and is based on geomagnetic data from two antipodal stations, Hartland (England) and Canberra (Australia). Monthly zonal-mean zonal wind and zonal-mean temperature data were created by averaging the appropriate variables from the NCEP/NCAR Reanalysis data set (Kalnay et al. 1996), available from the NOAA-CIRES Climate Diagnostics Center website (http: //www.cdc.noaa.gov/cdc/reanalysis). The zonal wind and temperature data are available for 17 geopotential heights ranging from $1000 \mathrm{hPa}$ to $10 \mathrm{hPa}$, and $2.5^{\circ}$ intervals of latitude and longitude. The data for the QBO, which consist of equatorial $30 \mathrm{hPa}$ zonal wind values, were obtained from the Joint Institute for the Study of the Atmosphere and Ocean (JISAO) website (http://tao.atmos.washington.edu/data_sets/ qbo/) and are provided by Barbara Naujokat.

A five point unweighted moving average (i.e. with a halfwidth of two years) was used to facilitate the study of geomagnetic activity forcing of the NAM at different time scales.
Decadal variations were isolated by applying the moving average to the year-to-year variations for each month for both the NAM and AA indices. Short-term (two-to five-year) variations were isolated by subtracting the smoothed data from the original indices. The use of the moving average resulted in the loss of the last two years of data. Therefore decadal and interannual versions of the AA and NAM indices only extend to 1997.

The results of Bucha and Bucha (1998) indicate that the relationship between the geomagnetic AA index and the NAO index, which is tantamount to the NAM index, is not constant over time. Therefore, the temporal nature of the relationship between the AA and NAM indices has been examined objectively for each month using sliding correlations for the decadal (smoothed) data and the cumulative sum of the squares of deviations for the interannual data. For the sliding correlations, 11-year windows were used so that at least one complete decadal cycle was covered, with one-year increments. The cumulative sums technique is demonstrated in Taylor et al. (2002), who developed it to extract a weak climatic signal from ecological data. It involves calculating the sum of the squares of the differences between two normalised time series. The slope of the cumulative sums reflects the strength of the correlation; uncorrelated data results in a slope of two, while strong positive correlations produce a slope close to zero (Taylor et al., 2002). Although the cumulative sums technique is not widespread in climate research, or well-developed in the literature, it is used in this instance because the sliding correlations method is inappropriate for the noisy interannual data. Sliding correlations performed on the interannual data (not shown) using both 11-year and 5-year windows yield highly variable, very low correlations that provide no information about the temporal aspect of possible correlations between geomagnetic activity and the NAM. The cumulative sums method is more dynamic because it is not necessary to specify a window width, and abrupt changes in the relationship between the two time series are well represented by the slope of the cumulative sums line.

One of Pittock's (1978) guidelines to solar-climate researchers emphasises the need to "critically examine the statistical significance of the result, making proper allowance for...autocorrelation and smoothing...”. Serial correlation was taken into consideration when performing $t$-tests on correlation coefficients by replacing the actual number of observations with the effective number of observations $\left(N_{\text {eff }}\right)$, which was calculated as follows (from Slonosky et al., 2000):

$N_{\mathrm{eff}}=N \times \frac{\left(1-r_{1} r_{2}\right)}{\left(1+r_{1} r_{2}\right)}$,

where $N$ is the total number of observations, and $r_{1}$ and $r_{2}$ are the lag-one serial correlation coefficients of the two time series under consideration. The use of $N_{\text {eff }}$ is especially pertinent to the correlations involving smoothed data, as the smoothing processes greatly increases serial correlation in the data. 


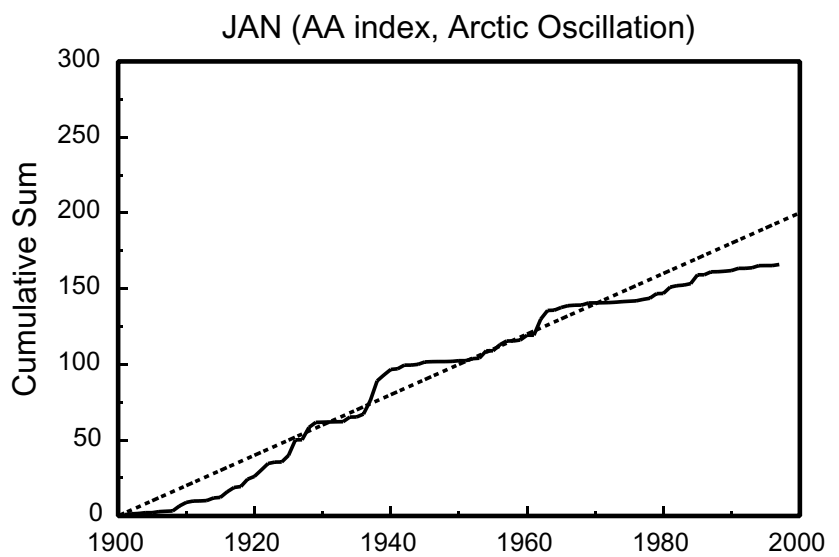

Fig. 2. The cumulative sum of squares for differences between the January interannual geomagnetic AA and NAM indices. The stippled line has a slope of two and represents uncorrelated data. The intervals from 1940 to 1950 and from the early 1960s onwards have a small slope, indicating that interannual variations of the geomagnetic AA index are well correlated to the interannual variations of the NAM index for those intervals.

\section{Results}

The magnitude and sign of the sliding correlations (Fig. 1) are highly variable with time, indicating that the relationship between geomagnetic activity and the NAM is temporally inconsistent, and that for most months and decades there is no link between the two geophysical parameters. One interval that stands out, however, is the period of positive correlations between the decadal January AA and NAM indices, from 1967 onwards. This indicates that decadal variations in the winter NAM (and NAO), evident since the 1960s, are inphase with decadal variations in geomagnetic activity. There is also a period of consistently high negative correlations between the decadal August AA and NAM indices from 1930 to 1960. Since our aim is to examine the role of solar-forcing in recent, unexplained winter circulation changes, we do not discuss the results for the August data further. We note, however, that the correlations for the August data between 1930 and 1960 are strong $(r<-0.60)$ on all time scales, and therefore, warrant future attention.

The cumulative sums, calculated for the interannual data, show a similar seasonal and temporal pattern as the sliding correlations. The results for January (Fig. 2), in particular, display intervals during which the interannual variations in the AA and NAM indices are correlated. The slope of the cumulative sums is shallow (and hence, the correlations are strong) between 1940 and 1950 and from the early 1960s onwards.

For the original (unmodified) January AA and NAM indices, the correlation coefficient between the two series from 1965 to 1997 is $0.62\left(N_{\text {eff }}=28\right)$, which is statistically significant from zero at the $95 \%$ confidence level when Neff is used. Correlations for the interannual variations for the same period $\left(r=0.49 ; N_{\text {eff }}=33\right)$ are also statistically signif-

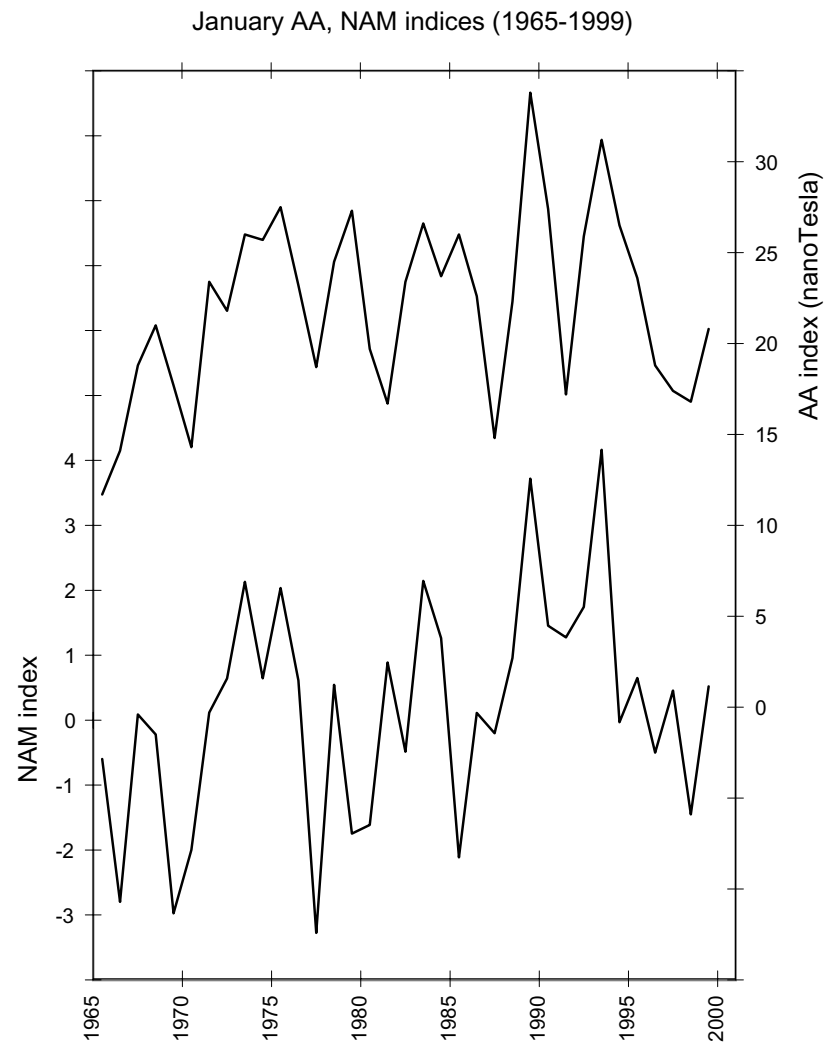

Fig. 3. The January geomagnetic AA index (top) and the January NAM index (bottom), from 1965-1999. The correlation coefficient between these two time series is 0.62 , which is statistically significant at the $95 \%$ confidence level.

icant from zero at the $95 \%$ confidence level. The correlation coefficient for the 1965 to 1997 decadal data $(r=0.82)$ does not yield statistically significant results due to the limited number of effective observations $\left(N_{\text {eff }}=5\right)$. This is a result of the smoothing process employed to extract the decadal variations, which has enhanced the already high serial correlation in both the AA and NAM indices. The strong correspondence between the January AA and NAM indices, from the mid 1960s onwards, is shown in Fig. 3. Correlation coefficients for other months, even December and February, are considerably lower and do not achieve statistical significance on any time scale.

When describing links between the solar cycle and the lower atmosphere, much of the modern literature indicates that the QBO plays an important role, modulating solarclimate relationships based on the direction of the QBO winds (Labitzke and van Loon, 2000). It is not clear, however, if geomagnetic forcing of the lower atmosphere is also contingent on the phase of the QBO, especially since the results so far have yielded statistically significant and relatively robust results without any consideration of the QBO. A strong improvement in the results was evident, however, when the January data were separated according to the phase of the QBO (Fig. 4). When the QBO phase is easterly, the January AA and NAM indices are strongly correlated 

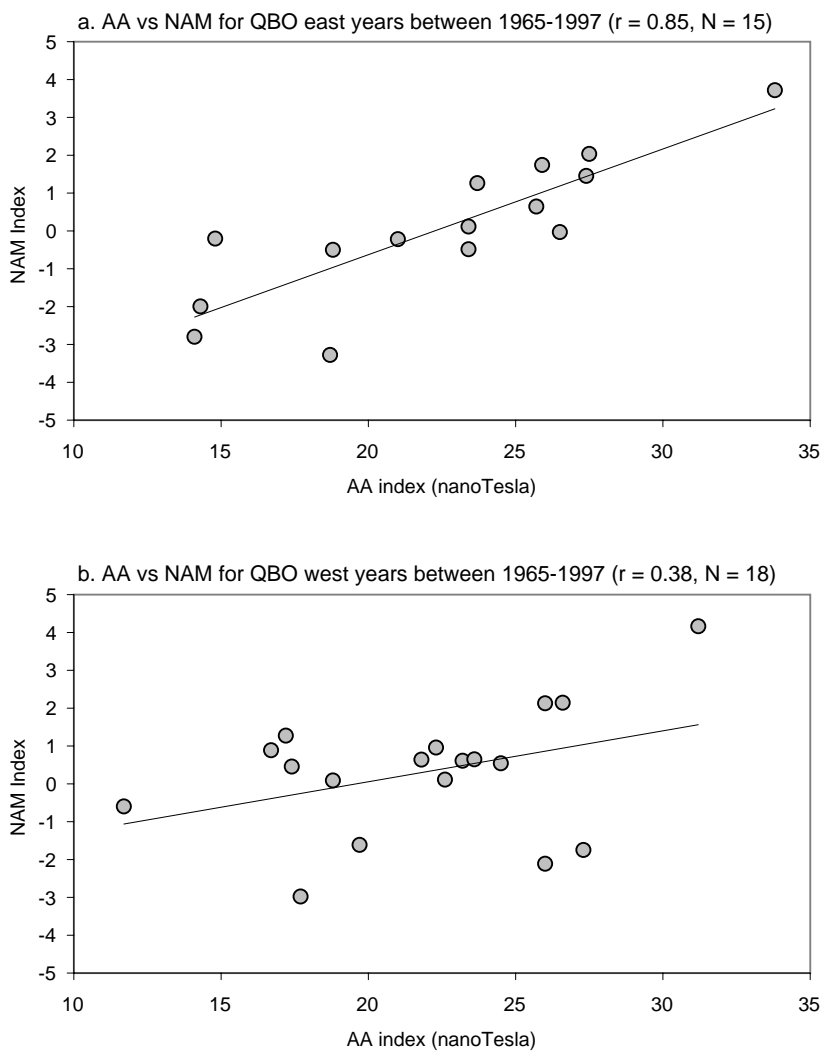

Fig. 4. Scatter plot of the January geomagnetic AA index and the January NAM index from 1965-1997 for (a) Januaries in which the QBO winds are easterly, and (b) Januaries in which the QBO winds are westerly. The correlation coefficient between these two time series for the QBO east years is 0.85 , which is statistically significant at the $95 \%$ confidence level. Conversely, the correlation for the QBO west years is only 0.38 and is not statistically significant at the $95 \%$ confidence level.

$(r=0.85, N=15)$. This correlation is statistically significant from zero at the $95 \%$ confidence level, and the improvement in correlation magnitude over the unseparated data is not a function of the reduced sample size. This is evident because the original January AA and NAM indices for QBO west data are poorly correlated $(r=0.38, N=18)$ and do not achieve statistical significance at the $95 \%$ confidence level. Incorporating the QBO into analysis for other boreal winter months did not appreciably improve the magnitude of the correlation coefficients.

Our analyses so far have revealed that strong correlations between the geomagnetic AA index and the NAM only occur in January, are restricted to periods after the early 1960s (though interannual variations show some correspondence between 1940 and 1950), and are strongest during the QBO east phase. We now examine the spatial signature of geomagnetic activity forcing on zonal-mean zonal wind and temperature data from 1965-1997. Correlations between the unmodified AA index and zonal-mean zonal wind data from the NCEP/NCAR reanalyses are shown for December and January in Figs. 5a and 5b. In all cases, $N=33$, requiring an approximate correlation coefficient of 0.35 for a statistical significance at the 95\% confidence level. The effective number of observations is not considered because the data have not been smoothed and the zonal wind time series are not strongly serially correlated. These correlations include data for both phases of the QBO, and therefore, incorporate all years from 1965 to 1997 in order to capture both the decadal and the interannual similarities between the AA and the NAM. When restricted to interannual data for the QBO east phase only, the signature of geomagnetic activity is generally the same but the January correlation coefficients are greater (not shown). The geomagnetic activity signature in the January zonal-mean zonal wind data matches that of the NAM. It is characterised by a broad area of positive correlations between $45^{\circ} \mathrm{N}$ and $65^{\circ} \mathrm{N}$, and an area of negative correlations between $15^{\circ} \mathrm{N}$ and $40^{\circ} \mathrm{N}$. Although these correlations extend beyond the troposphere into the lower stratosphere, statistically significant coefficients are limited to altitudes below $\sim 20 \mathrm{~km}$.

The dipole pattern of correlations in December, however, is strongest in the stratosphere and is statistically significant only above altitudes of $\sim 12 \mathrm{~km}$. Christiansen (2002) indicated that zonal-mean zonal wind anomalies at a geopotential height of $10 \mathrm{hPa}$ and a latitude of $60^{\circ} \mathrm{N}$ influence the phase of the Arctic Oscillation 30 days later. The correlations shown in Fig. 5a for December encompass this area, and suggest that zonal-mean zonal wind variations resulting from geomagnetic activity can influence the January zonal wind field. The correlation between the geomagnetic AA index and the zonal-mean zonal wind at this particular point $\left(60^{\circ} \mathrm{N}, 10 \mathrm{hPa}\right.$ ) is 0.44 . Correlations for other months (not shown) do not show a pattern similar to the NAM signature in zonal-mean zonal wind, and generally lack statistically significant correlations. We note, however, that although the December geomagnetic activity has some influence on tropospheric circulation in January (as represented by the NAM index), geomagnetic activity in January still has a stronger influence. For instance, the correlation between the January NAM index and the December AA index is $0.41\left(N_{\text {eff }}=31\right)$, which is statistically significant at the $95 \%$ confidence level, and confirms that the impact of geomagnetic activity on December circulation (Fig. 5a) is carrying forward to the following Januaries, shown in Fig. 5b. However, the correlation between the January NAM and AA indices (presented earlier as $r=0.49$ ) is even stronger, indicating that geomagnetic activity in January has a greater influence on January circulation than the follow-on effect from December.

The zonal-mean zonal wind changes associated with geomagnetic activity are accompanied by the zonal-mean temperature changes shown in Figs. 5c and 5d. In December, zonal-mean temperatures in the stratospheric polar night region (north of $60^{\circ} \mathrm{N}$ and above $10 \mathrm{~km}$ ) are negatively correlated to the AA index. Many of the correlation coefficients in this area are statistically significant at the $95 \%$ confidence level. These correlations are matched by positive correlations south of $60^{\circ} \mathrm{N}$, still above an altitude of $10 \mathrm{~km}$. In January, the largest correlation coefficients, and subsequently the only 
[a] DEC r(AA, zonal-mean zonal wind) 1965-97

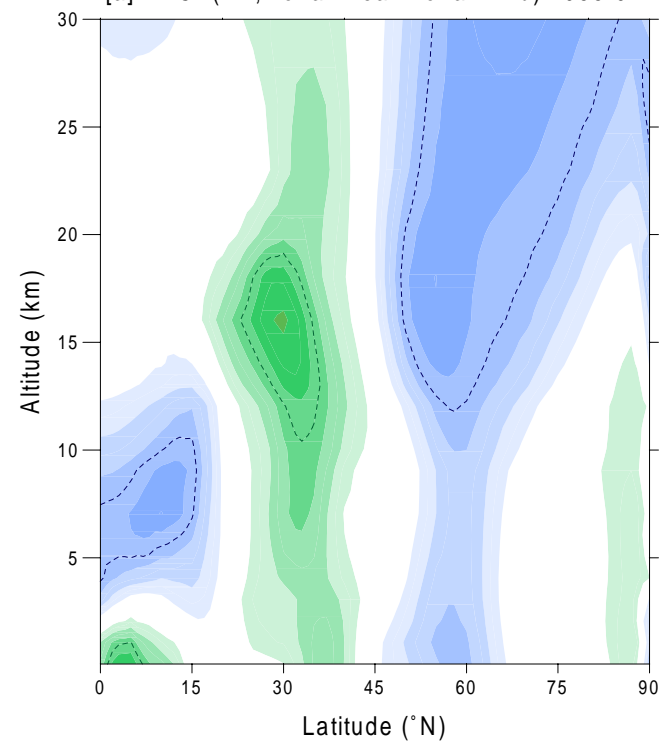

[b] JAN r(AA, zonal-mean zonal wind) 1965-97

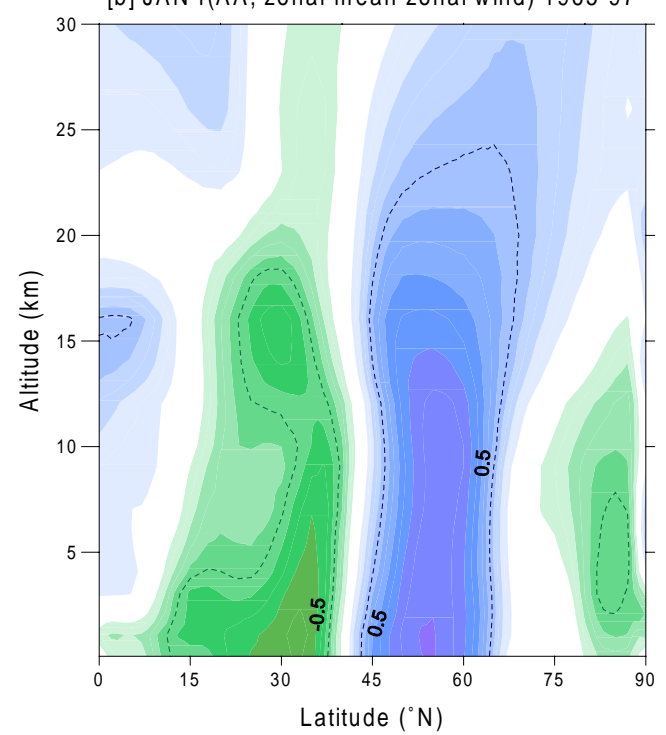

[c] DEC r(AA, zonal-mean temperature) 1965-97

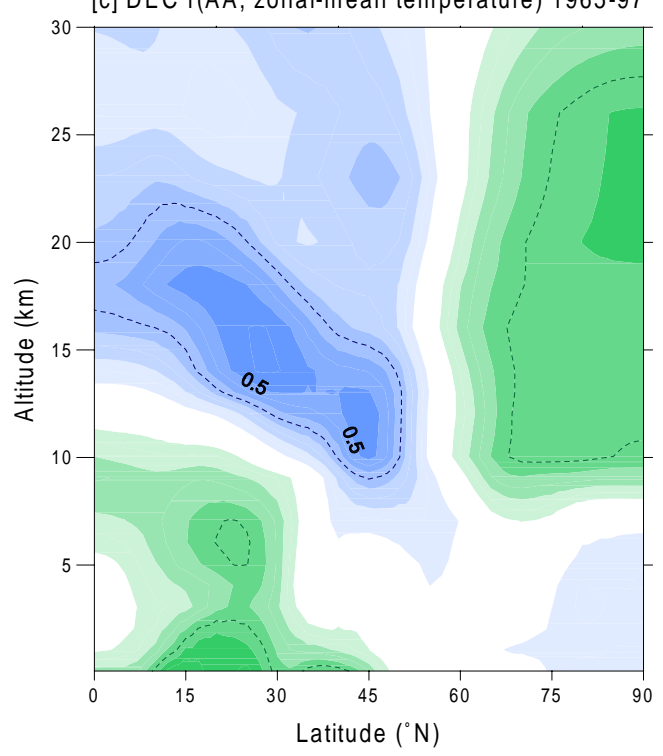

[d] JAN r(AA, zonal-mean temperature) 1965-97

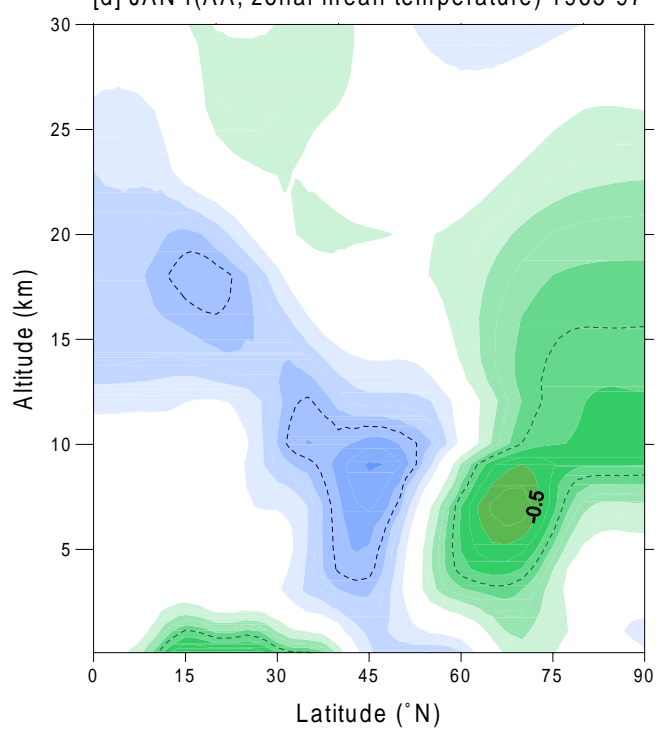

Correlation Coefficients

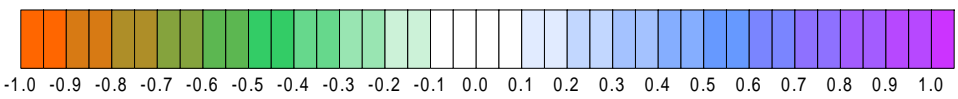

Fig. 5. Correlation coefficients between the geomagnetic AA index and (a) December zonal-mean zonal wind, (b) January zonal-mean zonal wind, (c) December zonal-mean temperature, (d) January zonal-mean temperature, from 1965-1997. The $r=0.35$ contour is indicated by a solid line, and represents the approximate threshold for statistical significance at the 95\% confidence level. (a) and (b) show that the geomagnetic activity signal is restricted to the stratosphere in December, but is most pronounced in the troposphere during January. The strong similarity between the geomagnetic activity signature in the January zonal-mean zonal wind data and the corresponding NAM signature confirms the reality of the relationship. (c) and (d) show the corresponding geomagnetic activity signal in temperature data. In December, temperatures in the stratospheric polar region are inversely correlated to the geomagnetic AA index. By modifying the latitudinal temperature gradient of the lower stratosphere, geomagnetic activity is coupled to the troposphere. This is evident in the January correlations, which are strongest in the upper troposphere. It appears that although the impact of geomagnetic activity on the December stratosphere influences tropospheric circulation in January through stratosphere-troposphere coupling, geomagnetic activity in January also impacts strongly on January zonal wind and temperature, as demonstrated by the correlations presented in the text. 
ones that are statistically significant, are found lower in the northern atmosphere, below $10 \mathrm{~km}$. This coincides with the spatial pattern of the maximum zonal-mean zonal wind correlations, and may reflect the downward propagation of geomagnetic activity induced anomalies from the stratosphere to the troposphere.

\section{Discussion}

There is a marked change in the NAM at the beginning of the 1960s associated with the onset of external forcing (Feldstein, 2002). By comparing the trend and variance of the winter NAM for the 1899-1967 period to that of the 19671997 period, Feldstein (2002) concludes that the interannual variability for the earlier period is derived from climate noise (i.e. internal forcing), and the latter period is characterised by external forcing. Feldstein (2002) associates the external forcing with either hydrosphere/cryosphere coupling to the atmosphere or with a source external to the climate system, such as changes in stratospheric aerosol or ozone concentration. We conclude that solar-modulated geomagnetic activity represents the external process that has forced part of the recent changes in the NAM and NAO.

Therefore, we attribute some of the winter trend in the NAM index to solar processes associated with geomagnetic activity, which also display an increasing trend since the mid 1960s. Similarly, the period of uncharacteristic low NAM values can be attributed to a concurrent low period in the AA index. The origin of the interannual variations in the NAM and NAO can also be explained in part by this relationship, at least for winters in which the QBO winds are easterly. Our findings allow us to present an alternative hypothesis regarding the origin of the decadal variations evident in North Atlantic climate parameters since the 1960s. Tourre et al. (1999) described a quasi-decadal frequency in sea surface temperature and sea level pressure variability in the Atlantic Ocean with a frequency of around 11.4 years. They presented a figure showing that, in recent years, variations at this frequency only occur after 1960 (see their Fig. 1b), and indicated that it represents an extension of the North Atlantic Oscillation. Similarly, Venegas and Mysak (2000) note a change in sea ice concentrations and sea level pressures in the North Atlantic between 1950 and 1960. Decadal variations in both of these climatic parameters are evident from 1960 onwards, but are predominantly a winter phenomenon. Through the analysis of Northern Hemisphere $500 \mathrm{hPa}$ geopotential heights, Knox et al. (1988) describe a climatic jump around 1962 that marks the abrupt beginning of a different climate regime. The strong correlations between the January AA and NAM indices from 1965 onwards suggest that the onset of solar forcing of the Northern Hemisphere circulation may be the cause of this regime change and the source of the decadal variations in North Atlantic climate.

We note that differences between our findings and those of Thejll et al. (2003), who deal with similar questions, are largely due to different analytical techniques and overall, our findings can be used as confirmation of earlier findings, including theirs. Thejll et al. (2003), for example, used a much wider window (31 years compared to our 11 years) for their sliding correlations, and subsequently placed the onset of the geomagnetic forcing at the early 1970s compared to our estimate of the mid-1960s. We also note that our use of monthly indices, rather than the seasonal indices used by Thejll et al. (2003), has allowed us to restrict the geomagnetic forcing of the Northern Hemisphere in the lower atmosphere specifically to January, whereas they have described it as a winter phenomenon. Finally, we have separated annual and decadal variations in our analyses, allowing us to incorporate the QBO into our correlations, and argue against the point made in Thejll et al. (2003) that the correlation is "driven by variability on time scales of 7-10 years", as we found strong correlations on interannual time scales when data corresponding to QBO's east years only were considered.

Our findings represent a solar-climate relationship that has practical, as well as statistical significance, evidenced by the importance of the NAM to Northern Hemisphere climate. The crucial question now relates to how solar/geomagnetic activity is coupled to the lower atmosphere. For part of this mechanism it is likely that geomagnetic activity influences the meridional temperature gradient, and subsequently the stratosphere zonal wind structure of the stratosphere, which, in turn, impacts upon tropospheric circulation through a number of possible processes outlined in Shindell et al. (2001) and Baldwin and Dunkerton (2001). The seasonality of the relationship is a function of stratospheretroposphere coupling, which only occurs during winter months.

Further research must consider how these stratospheric changes originate. Crucial to this endeavour is the elucidation of which physical processes in the atmosphere can be associated with geomagnetic activity. It is also important to explain the temporal pattern, as well as the role of the QBO in modulating the relationship.Therefore, we conclude that geomagnetic activity plays an important role in recent climate change, but that the mechanism behind this relationship needs further clarification.

Acknowledgements. D. Palamara would like to thank A. Golab for her revisions of the manuscript and comments regarding the research. The authors also thank the individuals and organisations that provided the atmospheric and solar data used in this study, and two anonymous reviewers for their comments and insights.

Topical Editor O. Boucher thanks two referees for their help in evaluating this paper.

\section{References}

Baldwin, M. P. and Dunkerton, T. J.: Stratospheric harbingers of anomalous weather regimes, Science, 294, 581-584, 2001.

Bucha, V. and Bucha, V.: Geomagnetic forcing of changes in climate and in the atmospheric circulation, J. Atmos. Solar-Terr. Phys., 60, 145-169, 1998. 
Christiansen, B.: On the physical nature of the arctic oscillation, Geophys. Res. Lett., 29, 10.1029/2002GL015208, 2002.

Feldstein, S. B.: The timescale, power spectra, and climate noise properties of teleconnection patterns, J. Climate, 13, 4430-4440, 2000.

Feldstein, S. B.: The recent trend and variance increase of the annular mode, J. Climate, 15, 88-94, 2002.

Greatbatch, R. J.: The north atlantic oscillation, stochastic environmental research and risk assessment, 14, 213-242, 2000.

Hurrell, J. W.: Decadal trends in the north atlantic oscillation: regional temperatures and precipitation, Science, 269, 676-679, 1995.

Hurrell, J. W.: Influence of variations in extratropical wintertime teleconnections on northern hemisphere temperature, Geophys. Res. Lett., 23, 665-668, 1996.

Kalnay, E., Kanamitsu, M., Kistler, R., Collins, W., Deaven, D., Gandin, L., Iredell, M., Saha, S., White, G., Woollen, J., Zhu, Y., Chelliah, M., Ebisuzaki, W., Higgins, W., Janowiak, J., Mo, K. C., Repelewski, C., Wang, J., Leetmaa, A., Reynolds, R., Jenne, R., and Jospeh, D.: The NCEP/NCAR 40-year reanalysis project, Bulletin of the American Meteorological Society, 77, 437-471, 1996.

Knox, J. L., Higuchi, K., Shabbar, A., and Sargent, N. E.: Secular variation of northern hemisphere $50 \mathrm{kPa}$ geopotential height, J. Climate, 1, 500-511, 1988.

Labitzke, K. and van Loon, H.: The QBO effect on the solar signal in the global stratosphere in the winter of the northern hemisphere, J. Atmos. Solar-Terr. Phys., 62, 621-628, 2000.

Marshall, J., Johnson, H., and Goodman, J.: A study of the interaction of the north atlantic oscillation with ocean circulation, J. Climate, 14, 1399-1421, 2001.

Mayaud, P.-N.: The aa indices: A 100-year series characterizing the magnetic activity, J. Geophys. Res., 77, 6870-6874, 1972. Perlwitz, J. and Graf, H.-F.: The statistical connection between tropospheric and strat ospheric circulation of the Northern hemi- sphere in winter, J. of Climate, Vol. 8, No. 10, 2281-2295, 1995.

Perry, A.: The north atlantic oscillation: An enigmatic see-saw, Prog. P. Geo., 24, 289-294, 2000.

Pittock, A. B.: A critical look at long-term sun-weather relationships, Rev. Geophys. Sp. Phys., 16, 400-420, 1978.

Shindell, D. T., Schmidt, G. A., Miller, R. L., and Rind, D.: Northern hemisphere winter climate response to greenhouse gas, ozone, solar, and volcanic forcing, J. Geophys. Res., 106, 71937210, 2001.

Slonosky, V. C., Jones, P. D., and Davies, T. D.: Variability of the surface atmospheric circulation over Europe 1774-1995, Int. J. Clim., 20, 1875-1897, 2000.

Stephenson, D. B., Pavan, V., and Bojariu, R.: Is the north atlantic oscillation a random walk?, Int. J. Clim., 20, 1-18, 2000.

Taylor, A. H., Allen, J. I., and Clark, P. A.: Extraction of a weak climatic signal by an ecosystem, Nature, 416, 629-632, 2002.

Thejll, P., Christiansen, B., and Gleisner, H.: On correlations between the north atlantic oscillation, geopotential heights, and geomagnetic activity, Geophys. Res. Lett., 30, 81-84 (doi:10.1029/2002GL016598), 2003.

Thompson, D. W. J., Wallace, J. M., and Hegerl, G. C.: Annular modes in the extratropical circulation, Part II: Trends, J. Climate, 13, 1018-1036, 2000.

Thompson, D. W. and Wallace, J. M.: Annular modes in the extratropical circulation. Part I: Month-to-month variability, J. Climate, 13, 1000-1016, 2000.

Tourre, Y. M., Rajagopalan, B., and Kushnir, Y.: Dominant patterns of climate variability in the atlantic ocean during the last 136 years, J. Climate, 12, 2285-2299, 1999.

Venegas, S. A. and Mysak, L. A.: Is there a dominant timescale of natural climate variability in the arctic? J. Climate, 13, 34123434, 2000.

Wunsch, C.: The interpretation of short climate records, with comments on the north atlantic and southern oscillations, Bulletin of the American Meteorological Society, 80, 245-255, 1999. 